NASA Technical Memorandum 106924

AIAA-95-2616

\title{
Use of the PARC Code to Estimate the Off-Design Transonic Performance of an Over/Under Turboramjet Nozzle
}

David W. Lam

Lewis Research Center

Cleveland, Ohio

Prepared for the

31st Joint Propulsion Conference and Exhibit cosponsored by the AIAA, ASME, SAE, and ASEE San Diego, California, July 10-12, 1995

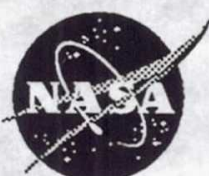

National Aeronautics and Space Administration 


\title{
USE OF THE PARC CODE TO ESTIMATE THE OFF-DESIGN TRANSONIC PERFORMANCE OF AN OVER/UNDER TURBORAMJET NOZZLE
}

\author{
David W. Lam ${ }^{*}$ \\ National Aeronautics and Space Administration \\ Lewis Research Center \\ Cleveland, $\mathrm{OH} 44135$
}

\begin{abstract}
$\underline{\text { Abstract }}$
The transonic performance of a dual-throat, singleexpansion-ramp nozzle (SERN) was investigated with the PARC computational fluid dynamics (CFD) code, an external flow Navier-Stokes solver. The nozzle configuration was from a conceptual Mach 5 cruise aircraft powered by four air-breathing turboramjets. Initial test cases used the two-dimensional version of PARC in Euler mode to investigate the effect of geometric variation on transonic performance. Additional cases used the two-dimensional version in viscous mode and the three-dimensional version in both Euler and viscous modes. Results of the analysis indicate low nozzle performance and a highly threedimensional nozzle flow at transonic conditions. In another comparative study using the PARC code, a single-throat SERN configuration for which experimental data were available at transonic conditions was used to validate the results of the over/under turboramjet nozzle.
\end{abstract}

\section{$\underline{\text { Symbols }}$}

$C_{f} \quad$ force coefficient normalized by the ideal force

$P_{0} \quad$ ambient static pressure

$P_{S} \quad$ ramp static pressure

$X \quad$ axial distance on ramp surface

$Y \quad$ normal distance on ramp surface

Subscripts:

$\begin{array}{ll}g & \text { gross } \\ x & \text { axial } \\ y & \text { normal } \\ \text { int } & \text { internal } \\ \text { ramp } & \text { nozzle ramp surface } \\ \text { cowl } & \text { cowl surface }\end{array}$

* Nozzle Technology Branch.

This paper is declared a work of the U.S. Government and is not subject to copyright protection in the United States.
Introduction

Recent advances in technologies required for hypersonic vehicles indicate that Mach 4 to 6 vehicles are now feasible. These advances have renewed interest in the development of hypersonic vehicles for both military and commercial applications. ${ }^{1}$ A new program was developed recently from the Inlets and Nozzle Concepts for Advanced Air-breathing Propulsion Systems ${ }^{2}$ study sponsored by the Air Force. This new joint program was conducted by the NASA Langley and NASA Lewis Research Centers to evaluate a Mach 5 waverider cruise vehicle ${ }^{3}$ (shown in Figure 1). Langley conducted the vehicle design and mission analysis activities, whereas Lewis estimated the installed propulsion system performance. One of the objectives of this program was to develop performance prediction methods for single- and dual-flow exhaust nozzle systems.

The propulsion system for the Mach 5 waverider used four of the over/under airbreathing turboramjet engines shown in Figure 2. For these types of propulsion systems, the exhaust nozzles must operate over nozzle pressure ratios (NPR, internal total pressure divided by ambient static pressure) varying from about 2 to 300 . A complexity arising from this propulsion concept is that both the turbojet and ramjet operate together, producing dissimilar nozzle flows, over a wide range of Mach numbers.

The wide operating range of this system requires a variable throat in each nozzle. Flaps or other mechanical devices can be used to vary the nozzle area, but they add weight to the exhaust system. One of the attractive advantages of using a single-expansion-ramp nozzle (SERN) instead of a conventional, twodimensional, convergent-divergent nozzle is that the underside aft region of the aircraft can be used as the expansion surface for the flow. This helps to reduce the overall weight of the vehicle. However, previous studies have shown that hypersonic SERN nozzles of this type generally have low thrust performance at transonic and low supersonic Mach numbers because the nozzles are overexpanded. ${ }^{4-8}$ 
The objective of the current work was to obtain initial nozzle performance data for the Mach 5 waverider and to optimize the nozzle at transonic conditions. The following sections present the procedures used and results obtained from this analysis.

\section{Nozzle Geometry and Flow Conditions}

Figure 3 shows the dual-throat turboramjet nozzle geometry used for this study, with its assumed variable geometry features. The RAO code ${ }^{13}$ (method of characteristics) was used to design and optimize the isentropic ramp contour at a design point of Mach 5 with the ramjet only. On the basis of this design point, the nozzle had a ramp length of $465 \mathrm{in}$. and an overall area ratio of 15 . The flap position separating the two internal flows at Mach 1.2 was based on the ramp contour at a design point of Mach 5 and the required throat areas at Mach 1.2 from the engine cycle deck. The throat heights for the turbojet and ramjet were determined to be 10.3 and 19.4 in., respectively, and the analysis assumed a rectangular cross-sectional throat area with a total width of 180 in. (45-in. wide for each of the four engines). The turbojet had an internal area ratio from the throat to the end of the splitter of 1.92 , whereas the ramjet had a ratio of 1.75 .

Tables 1 to 3 give the overall coordinates for the nozzle geometry. The inflow total and freestream conditions were based on engine data obtained from the cycle deck program. For the turbojet, the total pressure and temperature were $6778 \mathrm{lb} / \mathrm{ft}^{2}$ and $3897{ }^{\circ} \mathrm{R}$, respectively. For the ramjet, the total pressure and temperature were $1334 \mathrm{lb} / \mathrm{ft}^{2}$ and $3835^{\circ} \mathrm{R}$,

respectively. The freestream static pressure and temperature were $628 \mathrm{lb} / \mathrm{ft}^{2}$ and $412{ }^{\circ} \mathrm{R}$, respectively. The turbojet operated at an NPR of 10.8, whereas the ramjet operated at an NPR of 2.1.

Table 1 Coordinates for upper surface of turbojet and expansion ramp

[All dimensions given in feet.]

\begin{tabular}{|c|c|c|c|c|c|}
\hline$X$ & $Y$ & $X$ & $Y$ & $X$ & $Y$ \\
\hline 3.250 & 3.900 & 13.572 & 7.315 & 26.946 & 10.136 \\
\hline 4.337 & 4.052 & 14.505 & 7.580 & 27.929 & 10.279 \\
\hline 5.417 & 4.250 & 15.540 & 7.858 & 28.936 & 10.418 \\
\hline 6.546 & 4.779 & 16.683 & 8.149 & 29.964 & 10.553 \\
\hline 7.536 & 5.213 & 17.940 & 8.449 & 31.012 & 10.683 \\
\hline 8.637 & 5.662 & 19.313 & 8.757 & 33.158 & 10.929 \\
\hline 9.736 & 6.062 & 20.806 & 9.068 & 35.356 & 11.152 \\
\hline 10.458 & 6.315 & 22.418 & 9.380 & 36.469 & 11.255 \\
\hline 11.320 & 6.615 & 23.268 & 9.535 & 37.588 & 11.352 \\
\hline 12.349 & 6.951 & 25.053 & 9.840 & 38.709 & 11.442 \\
\hline
\end{tabular}

Table 2 Coordinates for bottom surface of turbojet

[All dimensions given in feet.]

\begin{tabular}{|c|c|}
\hline$X$ & $Y$ \\
\hline 3.250 & 3.042 \\
3.432 & 3.031 \\
3.613 & 3.020 \\
3.794 & 3.010 \\
3.975 & 3.000 \\
4.156 & 2.989 \\
4.337 & 2.979 \\
4.518 & 2.969 \\
4.698 & 2.958 \\
\hline
\end{tabular}$\quad$\begin{tabular}{|c|c|}
\hline 4.879 & 2.948 \\
5.058 & 2.937 \\
5.237 & 2.927 \\
5.417 & 2.917 \\
5.517 & 2.902 \\
5.617 & 2.887 \\
5.717 & 2.872 \\
5.817 & 2.857 \\
5.917 & 2.842 \\
\hline
\end{tabular}

Table 3 Coordinates for upper surface of ramjet [All dimensions given in feet.]

\begin{tabular}{|c|c|c|c|c|c|}
\hline$X$ & $Y$ & $x$ & $Y$ & $X$ & $Y$ \\
\hline-0.333 & 1.617 & 2.872 & 2.541 & 4.698 & 2.754 \\
\hline .055 & 1.757 & 3.072 & 2.570 & 4.879 & 2.767 \\
\hline .438 & 1.891 & 3.250 & 2.596 & 5.058 & 2.778 \\
\hline .812 & 2.010 & 3.432 & 2.622 & 5.237 & 2.791 \\
\hline 1.170 & 2.118 & 3.613 & 2.647 & 5.417 & 2.802 \\
\hline 1.511 & 2.212 & 3.794 & 2.671 & 5.517 & 2.809 \\
\hline 1.831 & 2.316 & 3.975 & 2.691 & 5.617 & 2.815 \\
\hline 2.127 & 2.401 & 4.156 & 2.710 & 5.717 & 2.821 \\
\hline 2.400 & 2.466 & 4.337 & 2.727 & 5.817 & 2.827 \\
\hline 2.648 & 2.506 & 4.518 & 2.741 & 5.917 & 2.833 \\
\hline
\end{tabular}

\section{Computational Methods}

For the present study, the PARC code ${ }^{9}$ was used on the CRAY-YMP to determine the nozzle performance at Mach 1.2. PARC, an external flow Navier-Stokes solver based on the ARC code, ${ }^{10}$ can analyze a variety of propulsion flows. It can be operated in either Euler mode or full Navier-Stokes mode. PARC also allows for a variety of boundary conditions, making it a very versatile flow solver. For this study, the Thomas algebraic model ${ }^{11}$ was used as the turbulence model.

Figure 4 shows a typical two-dimensional computational grid generated by 3D INGRID ${ }^{12}$ and used for this study, and Figure 5 shows a typical three-dimensional grid. The two-dimensional grids had about 18000 grid points, whereas the threedimensional grids had about 500000 grid points. Only the grid points of the supersonic portion of the nozzle from the throat to exit were used in the computation. The analysis neglected the inner sidewalls separating the four engines for the three-dimensional cases. Upstream inflow conditions began at the throats of each nozzle and were fixed at their appropriate pressures and temperatures, whereas the downstream outflow condition was extrapolated. All the surfaces 
were considered to be slip walls for the Euler cases and to be no-slip, adiabatic walls for the viscous cases. The freestream boundary condition was used for the external flow of Mach 1.2.

A post-processing program calculated the parameters used to quantify the nozzle performance-the axial and normal force coefficients, $C_{f, x}$ and $C_{f, y}$. Figure 6 shows the control volume used for the analysis. For each directional force, the program calculated the internal stream thrust by integrating the momentum and pressures at the common exit plane. It calculated the ramp pressure force in a similar way by integrating the pressures on the ramp surface. The cowl boat-tail force was estimated assuming a Prandlt-Meyer expansion. These three individual force components (internal stream thrust, ramp force, and cowl force) all contributed to the overall gross force. The ideal force for each nozzle flow is a function of the throat area, NPR, and specific heat ratio. For the specific heat ratio, the average specific heat ratios of the turbojet and the ramjet were used. The overall ideal force was the sum of the individual ideal forces for the two nozzles. When the ideal force calculations changed less than 1 percent, the solution was considered to be converged. On the average, it took about 20000 iterations for each solution to converge.

\section{$\underline{\text { Results }}$}

The first configuration analyzed with the PARC2D code in Euler mode was the baseline case, where the cowl angle was set at $0^{\circ}$. Figure 7 shows a pressure mismatch between the exit planes of the turbojet and the ramjet. The turbojet flow is the dominant flow in this dual mode operation during transonic flight. As mentioned before, the turbojet is operating at an NPR of around 11, compared with an NPR of 2 for the ramjet. Because of the low ramjet exit pressure, the flow from the turbojet tends to expand locally into the ramjet flow. On the other hand, the ramjet flow is overexpanded, and an oblique shock appears at the trailing edge of the flap, splitting the two flows. Also, there seems to be a small local normal shock causing a subsonic region in the flow near the cowl exit of the ramjet.

In the axial direction (at a $0^{\circ}$ cowl angle), the gross force coefficient $C_{f, x, g}$ calculated was about 0.722 , indicating low nozzle performance. However, the internal stream thrust coefficient $C_{f, x \text {,int }}$ was quite high at 0.934 . The penalty came from the external expansion ramp, which produced a negative ramp force coefficient $C_{f, x, \text { ramp }}$ of -0.212 because of the overexpansion of the nozzle at Mach 1.2. In the normal direction, the gross force coefficient $C_{f, y, g}$ was about -0.847 . Similar effects were seen in this component as well where the expansion ramp produced a large negative force: $C_{f, y, \text { ramp }}$ was about -0.829 , whereas $C_{f, y \text {,int }}$ was only about -0.018 . The cowl boat-tail force was assumed to be zero in both directions since the cowl had $0^{\circ}$ deflection.

A first approach to improve the nozzle performance was to reduce the pressure difference at the exits of the two flows by increasing the local pressure that the turbojet was expanding into. The cowl of the ramjet was deflected upwards $5^{\circ}$ to increase the ramjet exit pressure by decreasing the exit area. A normal shock appeared inside the ramjet which helped minimize the pressure difference between the two flows due to the increase in ramjet exit pressure (Fig. 8). Consequently, $C_{f, x, g}$ improved slightly from the baseline configuration but was still low at 0.755 , and $C_{f, x, \text { int }}$ increased from 0.934 to 0.953 . The cowl deflection slowed down the expansion of the turbojet flow on the ramp, thus lowering $C_{f, x, \text { ramp }}$ to about -0.188 from -0.212 . However, the cowl deflection also caused a negative boat-tail force with a coefficient of -0.010 . As a result, the net effect in the axial force was a small increase over the baseline configuration. The $5^{\circ}$ cowl deflection had a greater effect in the individual forces in the normal direction. The normal internal stream thrust coefficient, $C_{f, y, \text { int }}$ increased from -0.018 to -0.121 , and $\mathrm{C}_{f, y, \text { ramp }}$ decreased from -0.829 to -0.771 . Also $\mathrm{C}_{f, y, \text { cowl }}$ increased from 0.000 to -0.112 . Overall, the gross normal force $C_{f, y, g}$ increased from -0.847 to -1.004 .

Another configuration was developed by deflecting the cowl at an angle that would equalize the pressures exiting from both nozzles. A one-dimensional analysis was used to determine the exit area from the exit static pressure (which equals the exit static pressure of the turbojet), total pressure, and throat area of the ramjet. The cowl angle associated with this new ramjet exit area was determined to be deflected upwards about $8.4^{\circ}$. The oblique shock at the end of the flap splitting the two flows was eliminated, and the turbojet flow no longer expanded into the ramjet flow as shown in Figure 9. The flow in the ramjet, however, stayed subsonic for the most part and did not become supersonic until it interacted with the freestream flow at the cowl exit. 
Once again, no significant changes were seen in the axial direction. The internal stream thrust, ramp pressure force, and boat-tail force coefficients were $0.961,-0.177$, and -0.026 , respectively. These three coefficients contributed to a $C_{f, x, g}$ of 0.758 , which was a slight increase from the baseline configuration at 0.722 but no dramatic change from the $5^{\circ}$ deflection at 0.755 . The changes were more apparent for the normal forces: $C_{f, y \text {,int }}$ increased to $-0.153, C_{f, y, \text { ramp }}$ decreased to -0.736 , and $C_{f, y, \text { cowl }}$ increased to -0.174 . However, these changes were not as significant when compared with the $5^{\circ}$ cowl deflection. Overall, the gross normal force coefficient $\mathrm{C}_{f, y, g}$ was about -1.063 .

Figure 10 compares the pressure distributions $P_{S} / P_{0}$ (ramp static pressure divided by ambient static pressure) along the expansion ramp at the cowl angle settings given in Figures 7 to 9 and Tables 4 and 5. The static pressures along the ramp did increase slightly as the cowl angle increased. This increase in pressure was reflected in the increase in the force coefficients. The effect was more significant in the normal direction than in the axial direction. However, the static pressures along the expansion ramp still stayed below the ambient static pressure. Tables 4 and 5 summarize the two-dimensional Euler performance calculations at the various cowl angles.

Because the ramp pressures always remained below the ambient pressure in the two-dimensional analysis, the next step was to investigate the three-dimensional relieving effect for the baseline configuration with PARC3D in Euler mode. The modeling of the freestream flow came into the calculation just at the cowl exit and downstream of that; this minimized the computational time. Also, only half the nozzle was modeled because the nozzle was symmetric along the expansion ramp. PARC3D predicted a significant pressure rise along the centerline of the expansion ramp, as shown in Figure 11, whereas the two-dimensional case always stayed below the ambient static pressure. Figures 12 and 13 show the Mach number contours along the centerplane and on the surface of the expansion ramp. The pressure rise tends to decrease away from the centerline. At transonic speed, the freestream helped pressurize the flowfield because the nozzle was highly overexpanded. The pressurization is reflected in the ramp force calculations.

The PARC3D configuration in Euler mode had a $C_{f, x, g}$ of 0.842 - significantly higher than the two-dimensional prediction of 0.722 -and had
Table 4 Axial force coefficients for

two-dimensional Euler analyses

\begin{tabular}{|c|r|r|r|r|}
\hline \multirow{2}{*}{$\begin{array}{c}\text { Cowl } \\
\text { angle, } \\
\text { deg }\end{array}$} & \multicolumn{4}{|c|}{ Axial force coefficients } \\
\cline { 2 - 5 } & $C_{f, x, \text { int }}$ & $C_{f, x \text { ramp }}$ & $C_{f, x, \text { owl }}$ & $C_{f, x, g}$ \\
\hline 0.0 & 0.934 & -0.212 & 0.000 & 0.722 \\
5.0 & .953 & -.188 & -.010 & .755 \\
8.4 & .961 & -.177 & -.026 & .758 \\
\hline
\end{tabular}

Table 5 Normal force coefficients for two-dimensional Euler analyses

\begin{tabular}{|c|c|c|c|c|}
\hline \multirow{2}{*}{$\begin{array}{c}\text { Cowl } \\
\text { angle, } \\
\text { deg }\end{array}$} & \multicolumn{4}{|c|}{ Normal force coefficients } \\
\cline { 2 - 5 } & $C_{f, y, \text { int }}$ & $C_{f, y, \text { ramp }}$ & $C_{f, y, \text { cowl }}$ & $C_{f, y, g}$ \\
\hline 0.0 & -0.018 & -0.829 & 0.000 & -0.847 \\
5.0 & -.121 & -.771 & -.112 & -1.004 \\
8.4 & -.153 & -.736 & -.174 & -1.063 \\
\hline
\end{tabular}

individual axial components, $C_{f, x \text {,int }}$ and $C_{f, x, \text { ramp }}$, of 0.951 and -0.109 , respectively. The performance in the normal direction was greatly improved: $C_{f, y, \text { int }}$ was calculated to be -0.027 , and $C_{f, y, \text { ramp }}$ was -0.241 , with an overall $C_{f, y, g}$ of -0.268 . Once again, the cowl boattail force was assumed to be zero in both directions for the $0^{\circ}$ cowl deflection. The axial and normal internal stream thrust coefficients, $C_{f, x}$ int and $C_{f, y, \text { int }}$ varied slightly between the two-and three-dimensional cases because different grid densities were used to minimize computation time. Ideally, the values would be the same for both cases.

The next approach in the study was to look at the viscous effects for the baseline configuration with PARC in both two and three dimensions. The grids were modified for the viscous configurations with tighter packing in the shear layer and near the wall surfaces. Figure 14 shows the Mach number contours for the two-dimensional viscous case. A boundary layer can be seen along the external expansion ramp. The flow seems to be separating near the exit of the ramjet both at the top and bottom surfaces. Also, the flow from the turbojet does not expand into the ramjet as much as in the two-dimensional Euler case at a cowl angle of $0^{\circ}$. For the force calculations in the axial direction, $C_{f, x, \text { int }}$ was about 0.947 and $C_{f, x, \text { ramp }}$ was about -0.205 , to give a $C_{f, x, g}$ of 0.742 . In the normal direction, $C_{f, y, \text { int }}$ and $C_{f, y, \text { ramp }}$ were determined to be -0.062 and -0.825 , respectively. The net force coefficient $C_{f, y, g}$ was -0.887 . The force coefficients were, however, slightly higher than for the two-dimensional Euler case. One reason might be that the grid was not packed closely enough near the wall 
surfaces to accurately capture the boundary layer. Overall, there were no real significant performance differences in the forces in comparison to the two-dimensional Euler case.

Figure 15 shows the centerplane Mach number contours for the three-dimensional viscous case. This figure is very similar to the two-dimensional viscous case with the exception that the flow separates along the expansion ramp. Figure 16 shows the pressure distribution comparison for the baseline configuration. The pressure rise for the three-dimensional viscous case was significantly higher than for the two-dimensional cases but slightly lower than for the three-dimensional Euler case. For the performance calculations in the axial component, $C_{f, x, \text { int }}$ was 0.906 and $C_{f, x, \text { ramp }}$ was -0.086 , to give a $C_{f, x, g}$ of 0.820 . In the normal component, $C_{f, y, \text { int }}$ was -0.078 and $C_{f, y, \text { ramp }}$ was -0.187 , to give a $C_{f, y, g}$ of -0.265 . In both components, $\mathrm{C}_{f \text {,cowl }}$ was assumed to be zero. The three-dimensional calculations were much more accurate than the twodimensional calculations, but there were no major differences between the Euler and viscous calculations. Tables 6 and 7 summarize the comparison between the Euler and viscous calculations for the baseline configuration.

\section{Evaluation of Methodology}

There was an uncertainty in the significant pressure rise for the over/under nozzle concept predicted by the three-dimensional PARC analysis. Another comparative study was done with a similar type of hypersonic nozzle for which experimental data

Table 6 Axial force coefficients for baseline configuration

\begin{tabular}{|l|l|r|r|r|}
\multicolumn{1}{c|}{$\left[C_{f, x, \text { cowl }}=0.\right]$} \\
\cline { 3 - 5 } & \multirow{2}{*}{ Mode } & \multicolumn{3}{|c|}{ Axial force coefficients } \\
\cline { 3 - 5 } & & $C_{f, x, \text { int }}$ & $C_{f, x \text { ramp }}$ & \multicolumn{1}{c|}{$C_{f, x, g}$} \\
\hline PARC2D & Euler & 0.934 & -0.212 & 0.722 \\
PARC2D & Viscous & .947 & -.205 & .742 \\
PARC3D & Euler & .951 & -.109 & .842 \\
PARC3D & Viscous & .906 & -.086 & .820 \\
\hline
\end{tabular}

Table 7 Normal force coefficients for baseline configuration

$$
\left[C_{f, y, \text { cowl }}=0 .\right]
$$

\begin{tabular}{|l|l|l|l|l|}
\hline \multirow{2}{*}{} & \multirow{2}{*}{ Mode } & \multicolumn{3}{|c|}{ Normal force coefficients } \\
\cline { 3 - 5 } & & $C_{f, y, \text { int }}$ & $C_{f, y, \text { ramp }}$ & $C_{f, y, 8}$ \\
\hline PARC2D & Euler & -0.018 & -0.829 & -0.847 \\
PARC2D & Viscous & -.062 & -.825 & -.887 \\
PARC3D & Euler & -.027 & -.241 & -.268 \\
PARC3D & Viscous & -.078 & -.187 & -.265 \\
\hline
\end{tabular}

were available at transonic conditions to validate the PARC results. The turbulence model used for this study was, once again, the Thomas algebraic model. The experimental work in reference 8 was conducted in the 8- by 6-Foot Supersonic Wind Tunnel at NASA Lewis on a National Aerospace Plane (NASP) type SERN with a single flow path (Figure 17). The nozzle, which was enclosed by sidewalls, was 8 -in. wide with a 1 -in.high throat that expanded to an internal area ratio of 1.29. The external expansion ramp was 8-in. wide and had an initial angle of $17^{\circ}$ and a trailing edge angle of $8^{\circ}$. The experimental conditions included various tunnel Mach numbers and NPR's, cold and hot flows, with and without external burning, and different nozzle configurations. The data point chosen was at a tunnel Mach number of 1.2 and an NPR of 10 for cold flow without external burning.

Experimental data showed a significant three-dimensional effect along the centerline of the expansion ramp at Mach 1.2 where the freestream interacted with the primary flow (Figure 18). The pressure rise decreased away from the centerline similar to the over/under turboramjet configuration. Once again, both the two- and three-dimensional versions of PARC were used in the computation. The PARC2D results underpredicted the static pressures along the expansion ramp. The three-dimensional results matched fairly well with the experimental data for pressures along the centerline. However, away from the centerline, PARC3D's predictions did not agree well with the experimental data. Also the overall pressure rise in the flowfield was not as high as the waverider's results, but nevertheless a three-dimensional effect was visible.

\section{Summary and Conclusions}

Several configurations of an over/under turboramjet nozzle concept were investigated with the PARC code in Euler mode and viscous mode with the Thomas model. Computational fluid dynamics (CFD) results show low-thrust performance at transonic flight conditions and a highly three-dimensional flowfield. The three-dimensional results agree qualitatively with the experimental data for the hypersonic nozzle at Mach 1.2. PARC accurately predicted the pressure rise along the centerline of the nozzle. The cowl deflection had a minimal benefit in the axial direction but had a larger negative effect in the normal direction. There were no significant differences in the nozzle performance calculations of the Euler and the viscous cases. Future CFD studies on these types of nozzles 
should utilize a three-dimensional analysis to accurately capture the three-dimensional effects at transonic conditions. An Euler analysis is sufficient for an initial parametric study.

\section{References}

1. Duchar, A.P.; and Wolf, J.P.: Preliminary Assessment of Exhaust Systems for High Mach (4 to 6) Fighter Aircraft. AIAA Paper 89-2356, July 1989.

2. Pegg, R.J., et al.: Design of a Hypersonic Waverider-Derived Airplane. AIAA Paper 93-0401, Jan. 1993.

3. Hagseth, P.E., et al.: Inlet and Nozzle Concepts for Advanced Air-breathing Propulsion Systems. WL-TR-92-3073, Apr. 1991.

4. Carboni, J.D., et al.: Supersonic Investigation of Two-Dimensional Hypersonic Exhaust Nozzles. NASA TM-105687, 1992.

5. Herrmann, H.; and Rick, H.: Propulsion Aspects of Hypersonic Turbo-Ramjet-Engines with Special Emphasis on Nozzle/Aftbody Integration. ASME Paper 91-GT-395, June 1991.

6. Eckert, E.; Göing, M.; and Scheitle, H.: Optimization of Hypersonic Thrust Nozzles. ISABE 91-7117.

7. Göing M.: Nozzle Design Optimization by Methodof-Characteristics. AIAA Paper 90-2024, July 1990.
8. Trefny, C.J.; and Carboni, J.D.: Results of a Single Expansion Ramp Nozzle With Hot Exhaust and External Burning. NASA TM-106390, 1994.

9. Cooper, G.K.; and Sirbaugh, J.R.: PARC Code: Theory and Usage. Arnold Engineering Development Center Report AEDC-TR-89-15, Arnold AFS, TN, Dec. 1989.

10. Pulliam, T.H.: Euler and Thin Layer Navier-Stokes Codes: ARC2D, ARC3D. Notes for Computational Fluid Dynamics User's Workshop, The University of Tennessee Space Institute, Tullahoma, Tennessee, (UTSI Publication E024005-023-84), 1984, pp. 15.1-15.85.

11. Thomas, P.D.: Numerical Method for Predicting Flow Characteristics and Performance of Nonaxisymmetric Nozzles-Theory. NASA CR-3147, Sept. 1979.

12. Dorrell, E.W., Jr.; and McClure, M.D.: 3D INGRID: Interactive Three-Dimensional Grid Generation. Amold Engineering Development Center Report AEDC-TR-87-40, Apr. 1988.

13. Nickerson, G.R.; Dang, A.L.; and Dunn, S.S.: The Rao Method Optimum Nozzle Contour Program. Contract No. NAS8-36863, prepared for George Marshall Space Flight Center by SEA, Inc., Feb. 1988. 

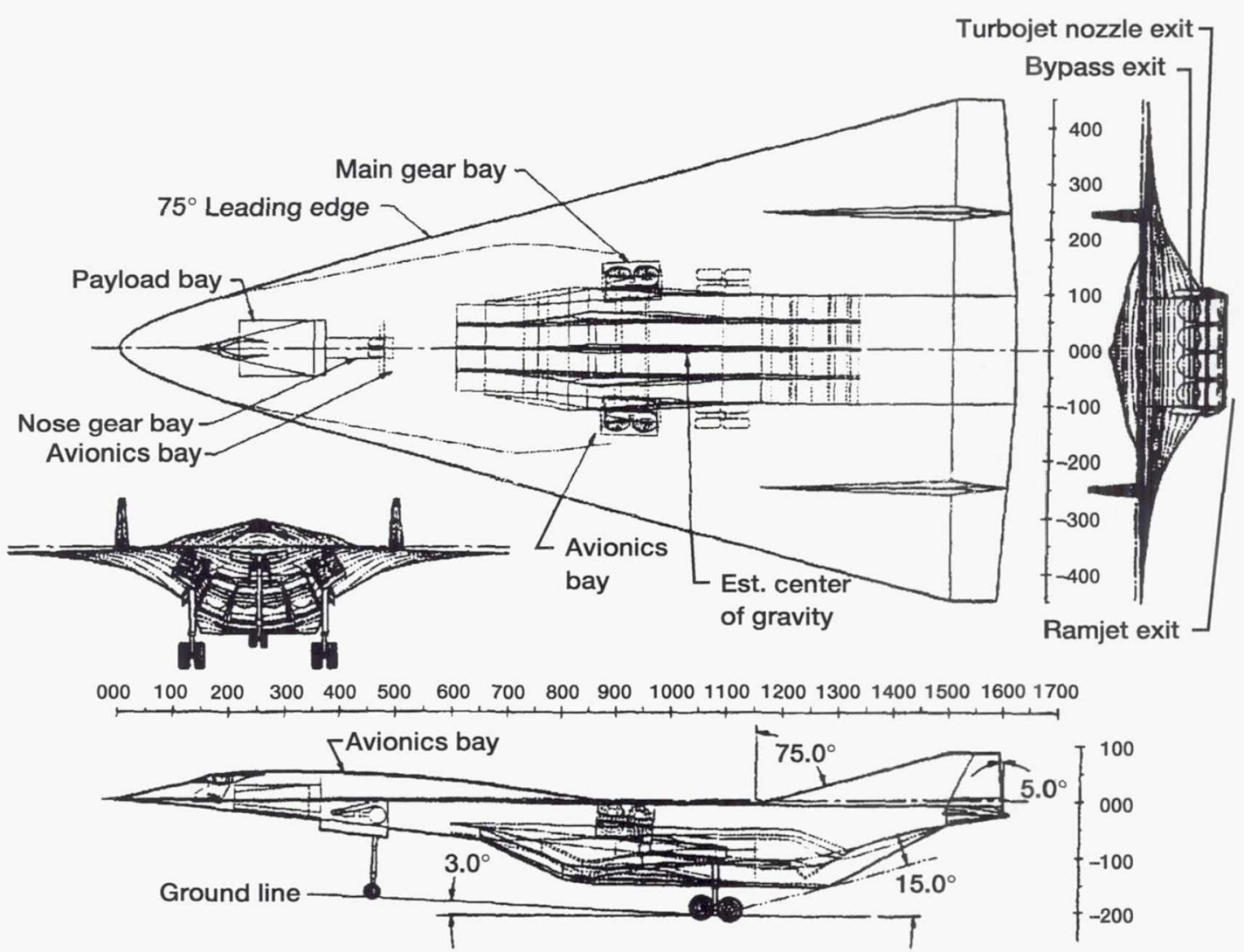

Figure 1.-Three views of the Mach 5 waverider cruise vehicle. ${ }^{2}$ (All dimensions given in inches unless marked otherwise.)

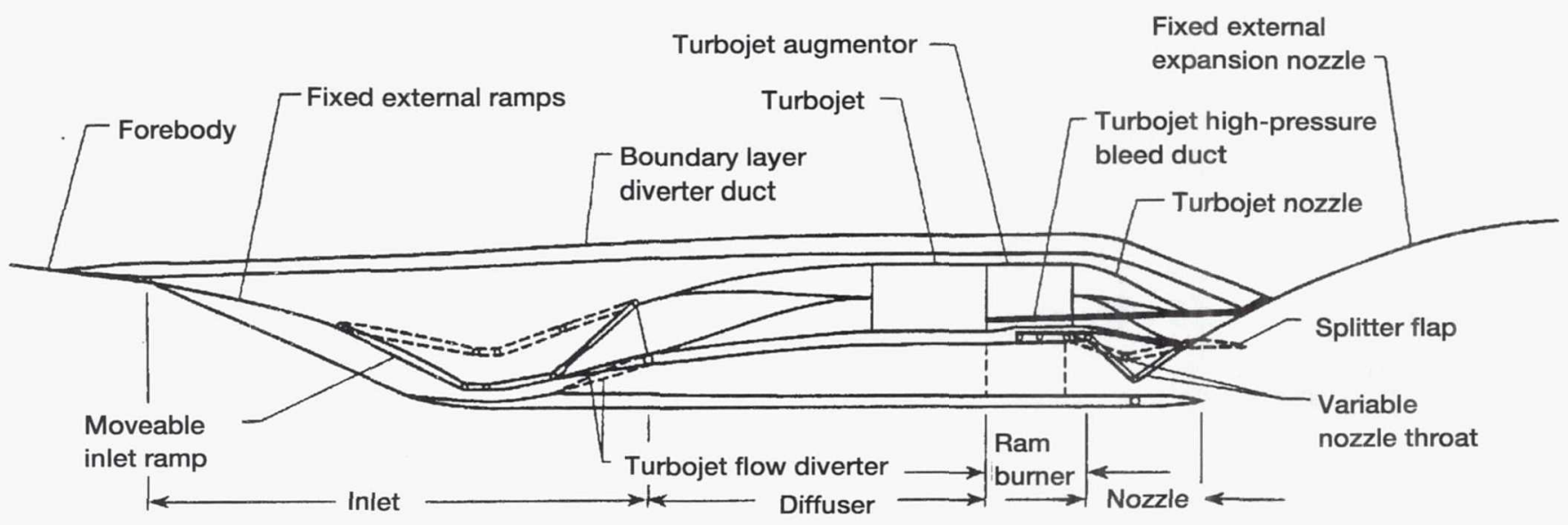

Figure 2.-Over/under turboramjet propulsion system. 


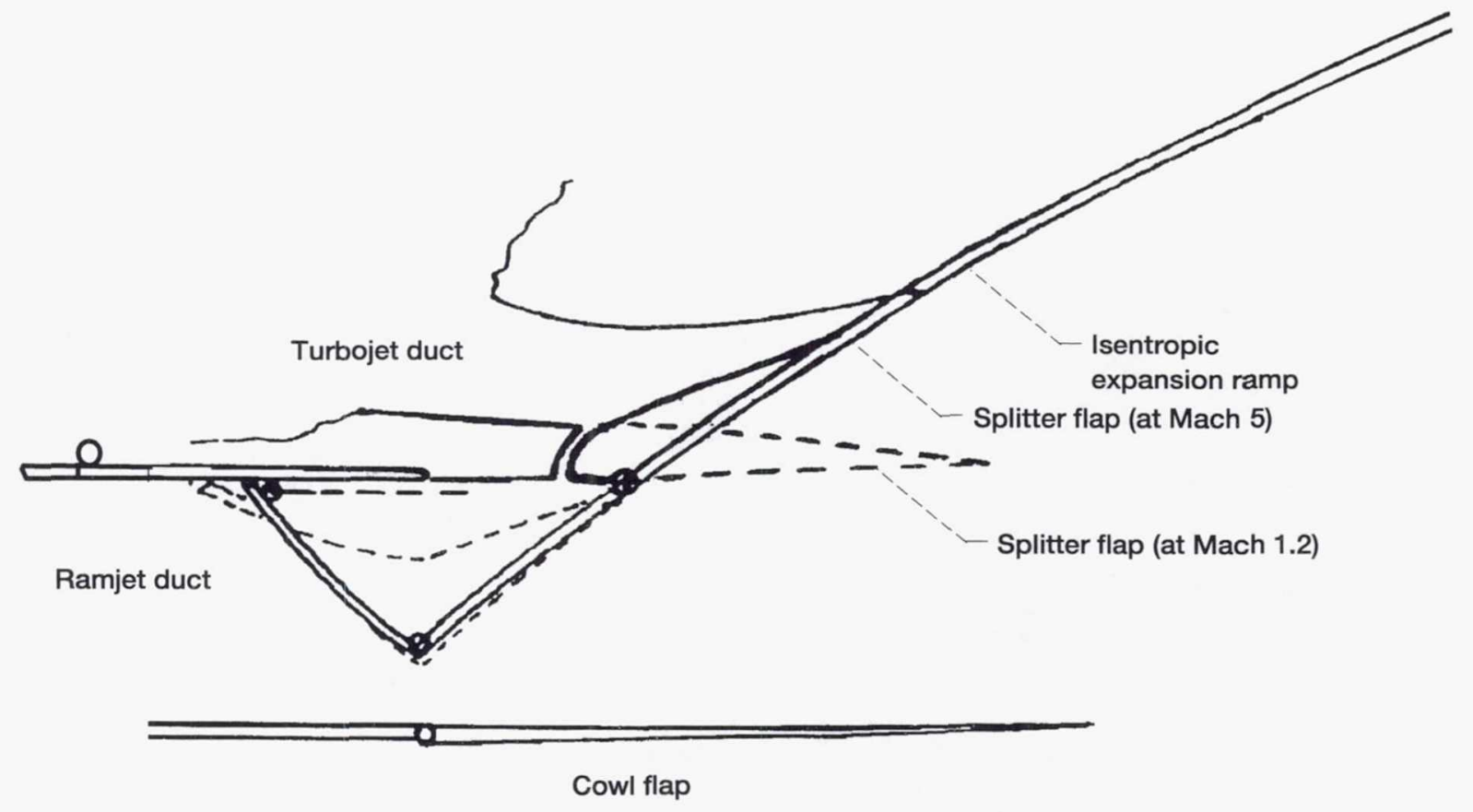

Figure 3.-Dual-throat turboramjet nozzle geometry.

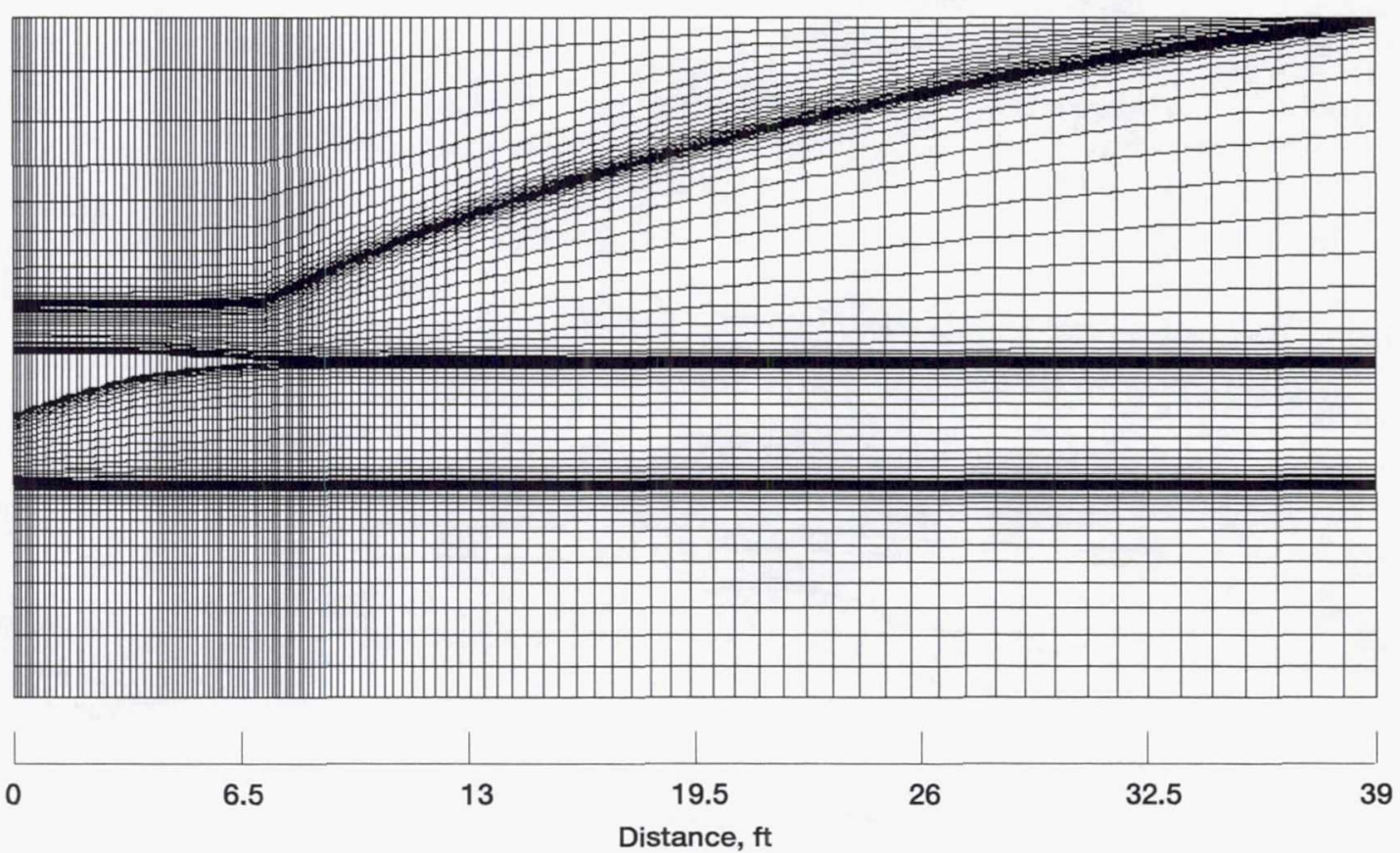

Figure 4.-Typical two-dimensional computational grid used for this study. 


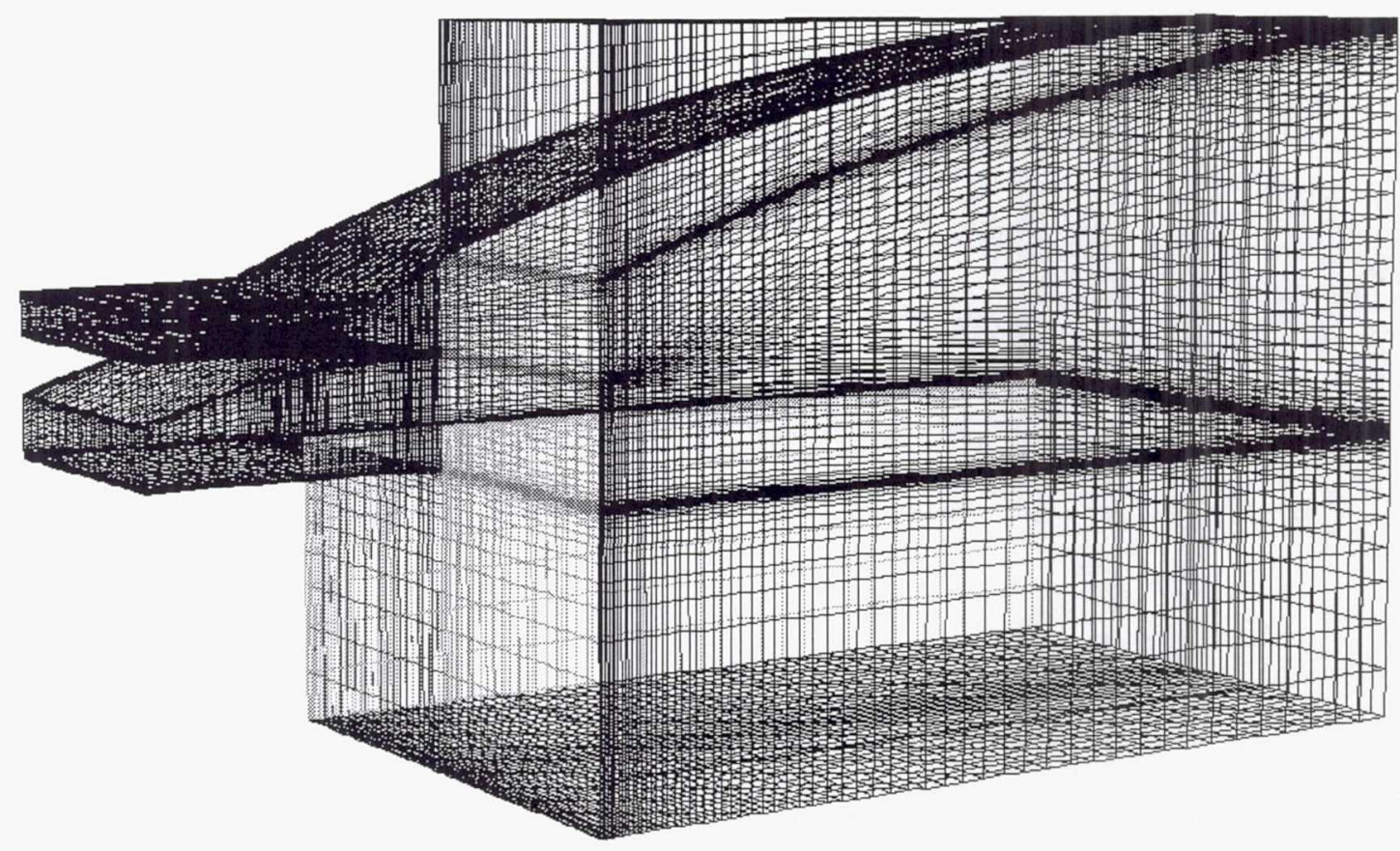

Figure 5.-Typical three-dimensional computational grid used for this study.

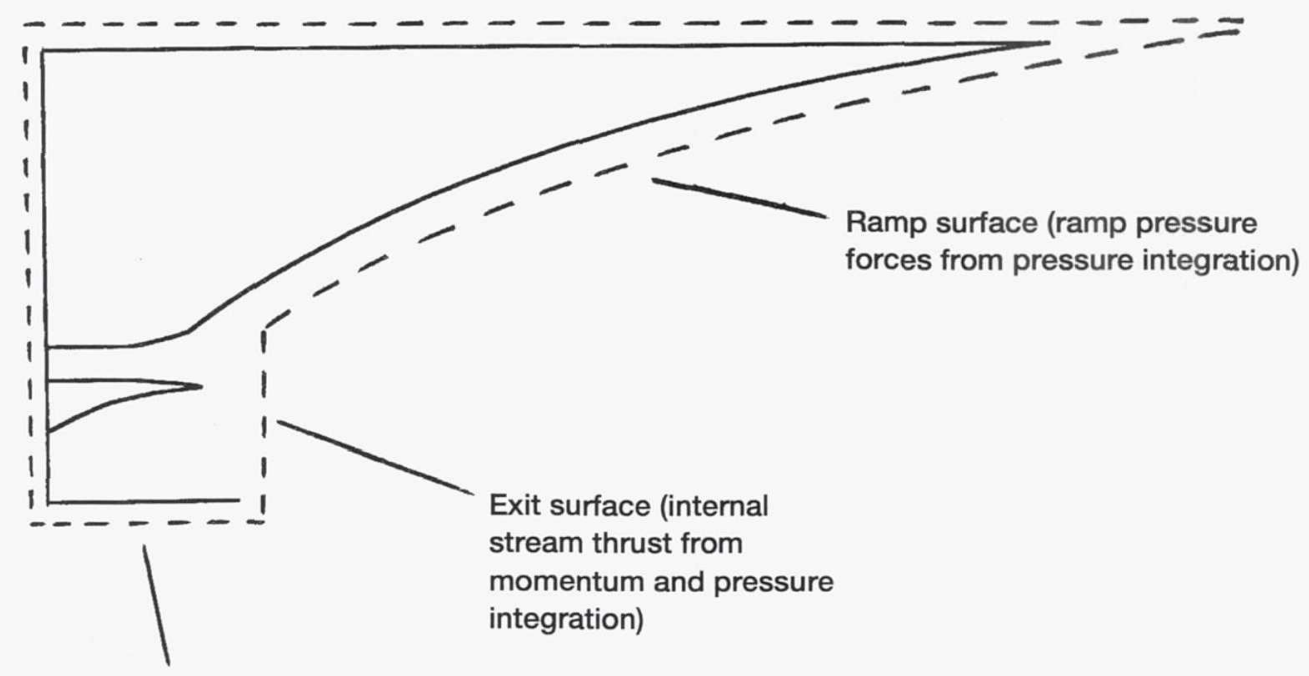

Boat-tail surface (cowl boat-tail pressure forces estimated)

Figure 6.-Control volume used for force calculations. 


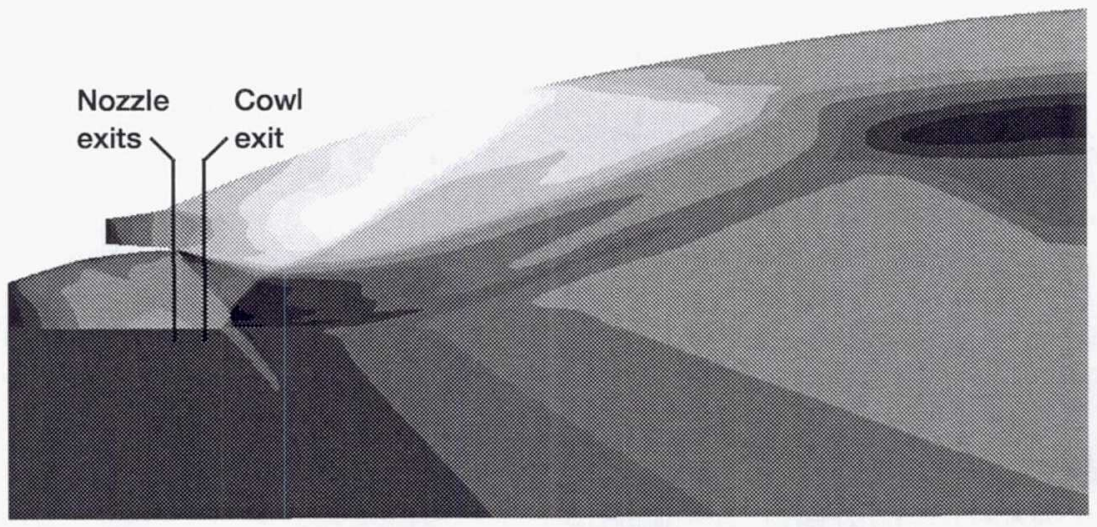

Mach number contour

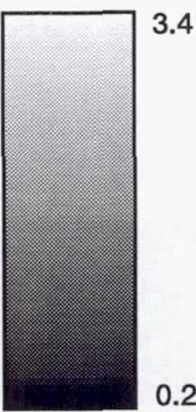

Figure 7.-Mach number contours for two-dimensional case in Euler mode at $0^{\circ}$ cowl angle.

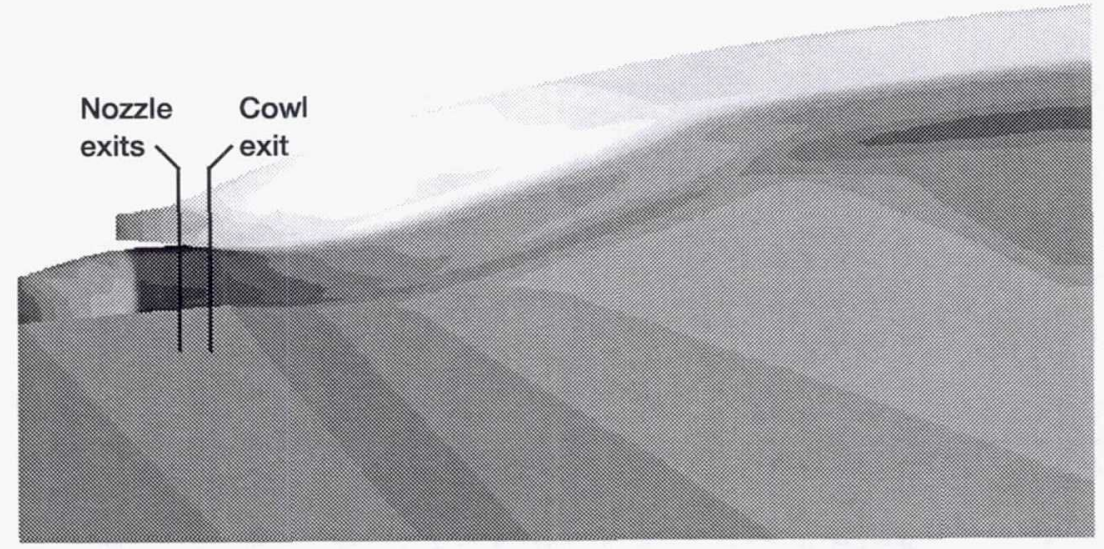

Mach number

contour

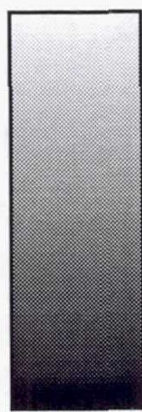

3.0

0.0

Figure 8.-Mach number contours for two-dimensional case in Euler mode at $5^{\circ} \mathrm{cowl}$ angle.
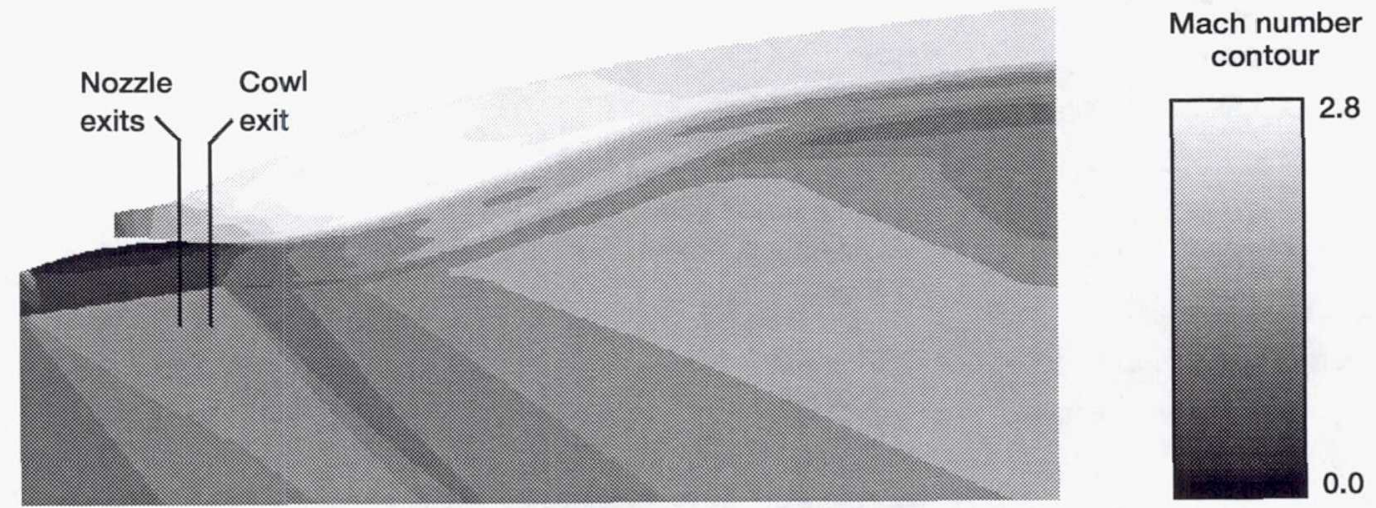

Figure 9.-Mach number contours for two-dimensional case in Euler mode at $8.4^{\circ} \mathrm{cowl}$ angle. 


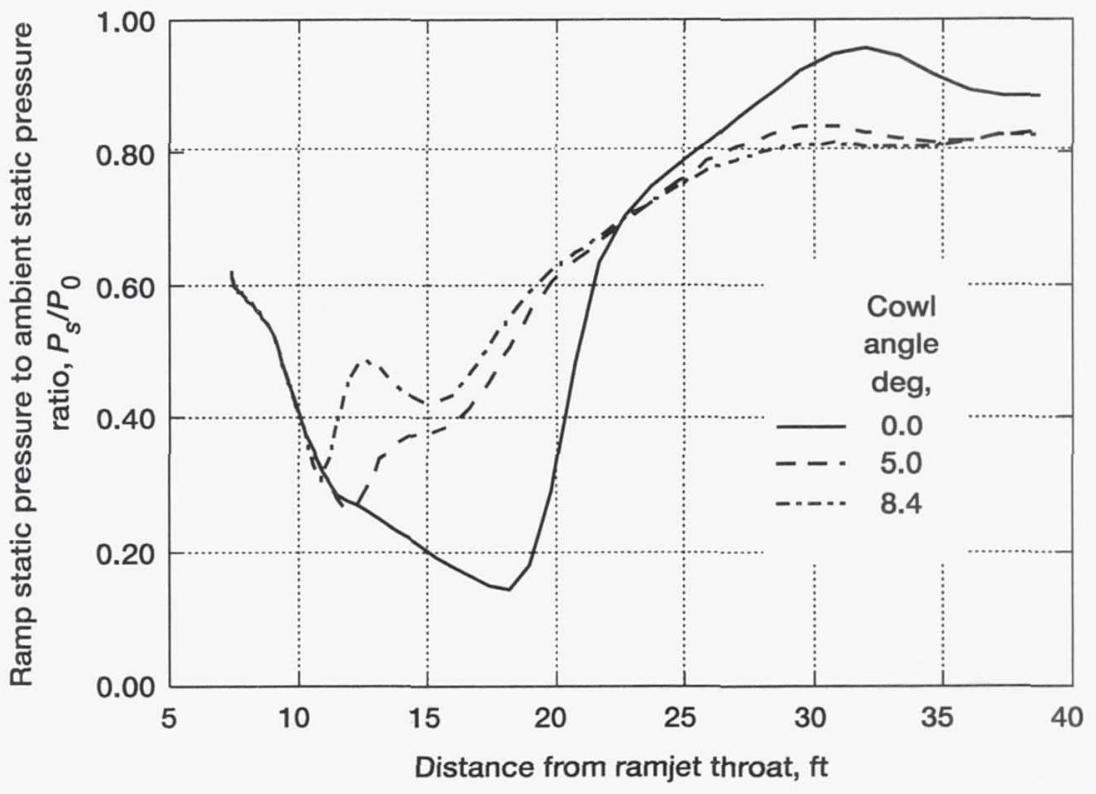

Figure 10.-Comparison of ramp pressure distributions for two-dimensional case in Euler mode at various cowl angles.

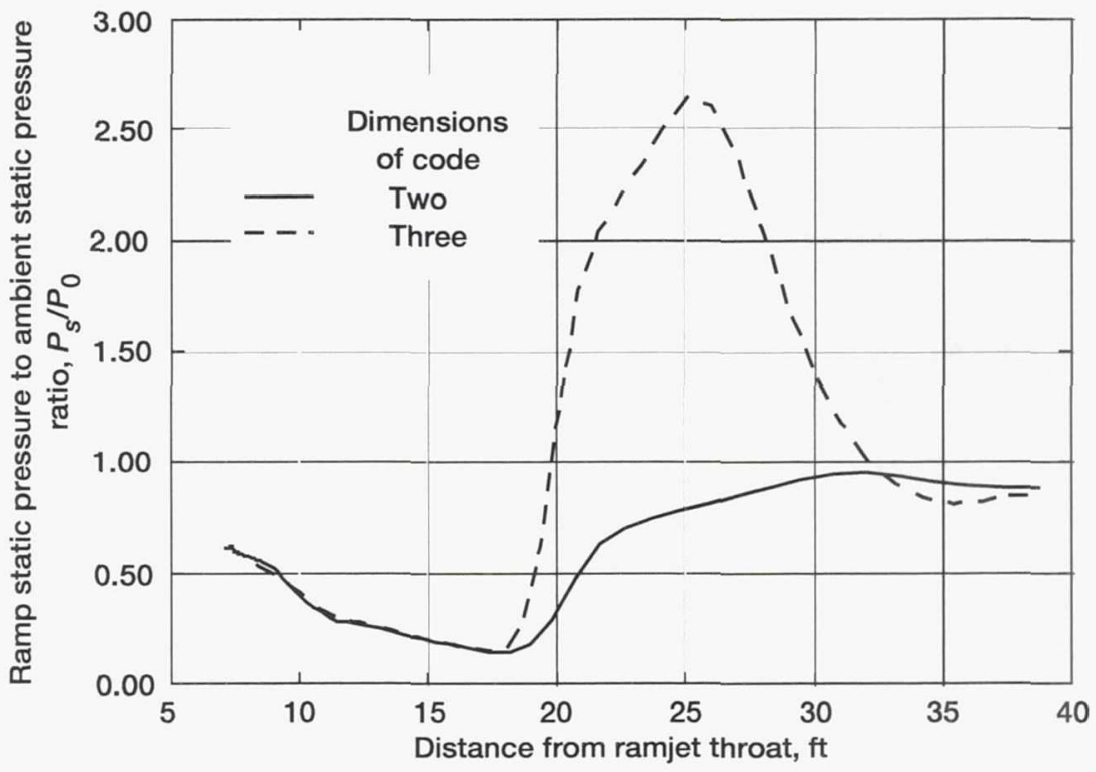

Figure 11.-Comparison of ramp pressure distributions for two- and threedimensional cases in Euler mode. 


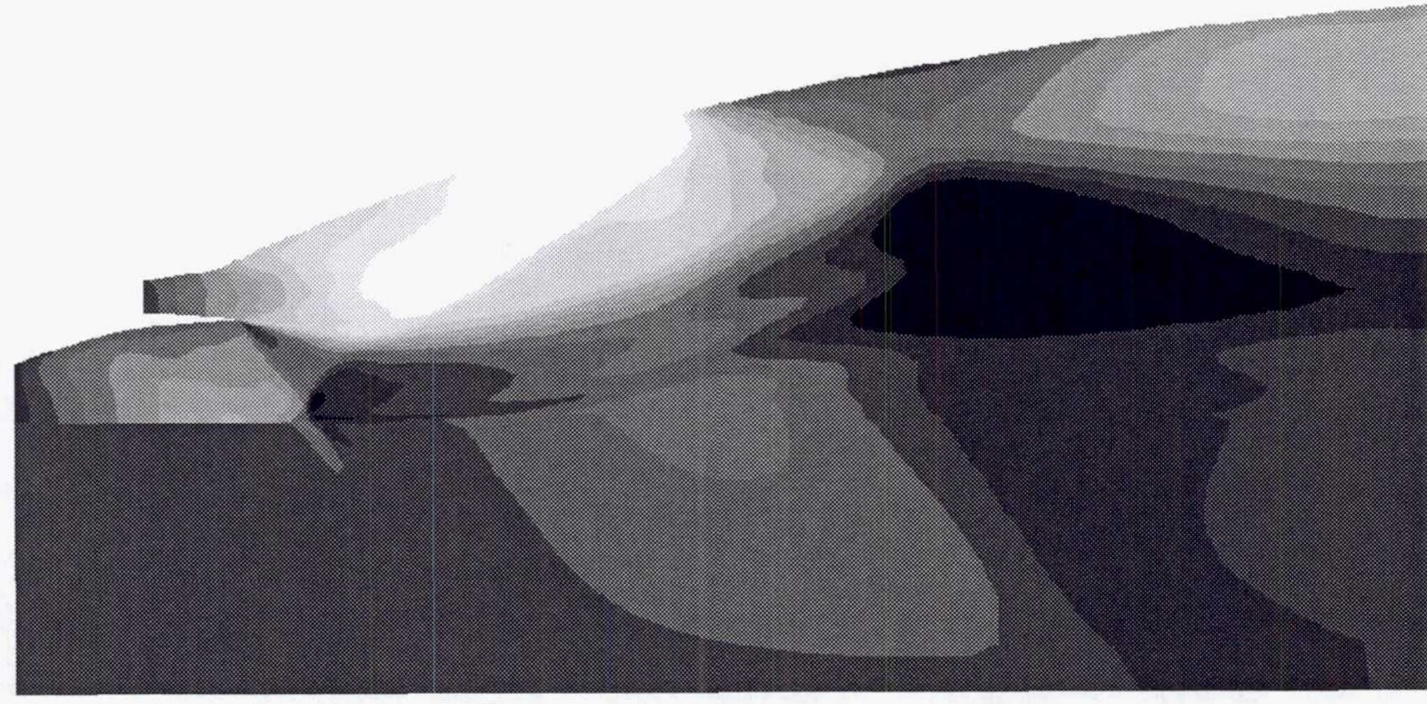

Mach number contour

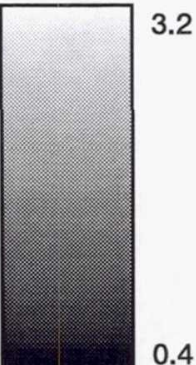

Figure 12.-Mach number contours along centerplane for three-dimensional case in Euler mode.

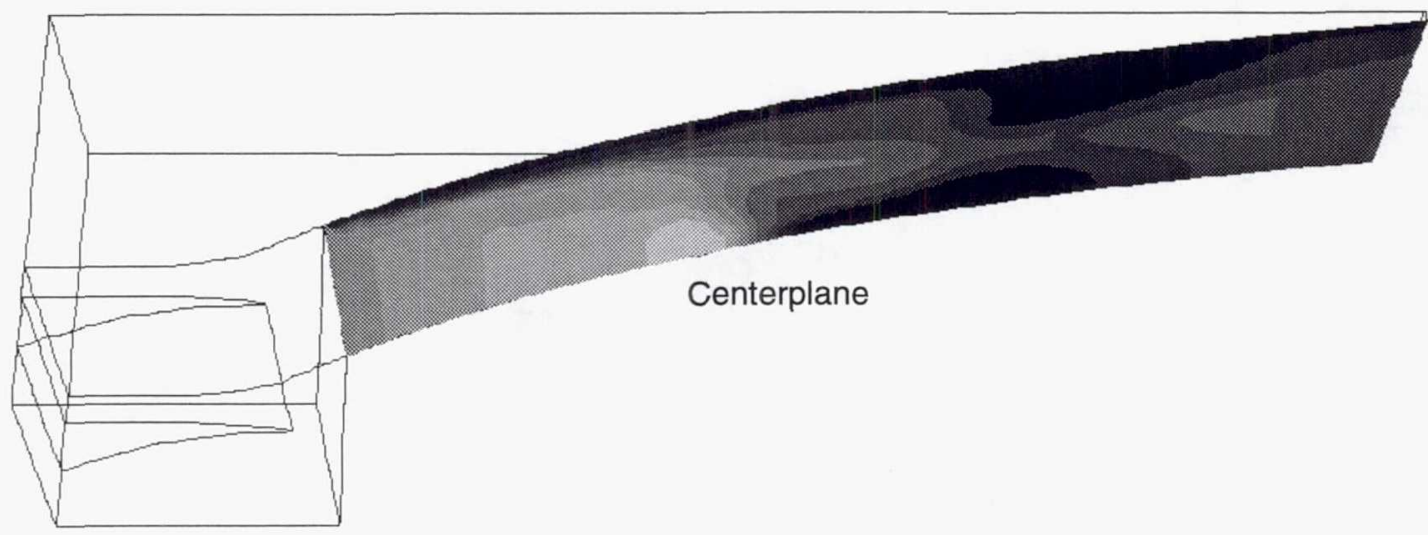

Mach number contour

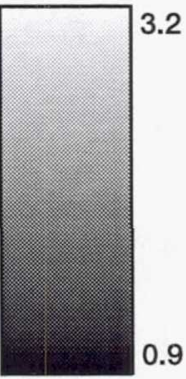

Figure 13.-Mach number contours along expansion for three-dimensional case in Euler mode. 


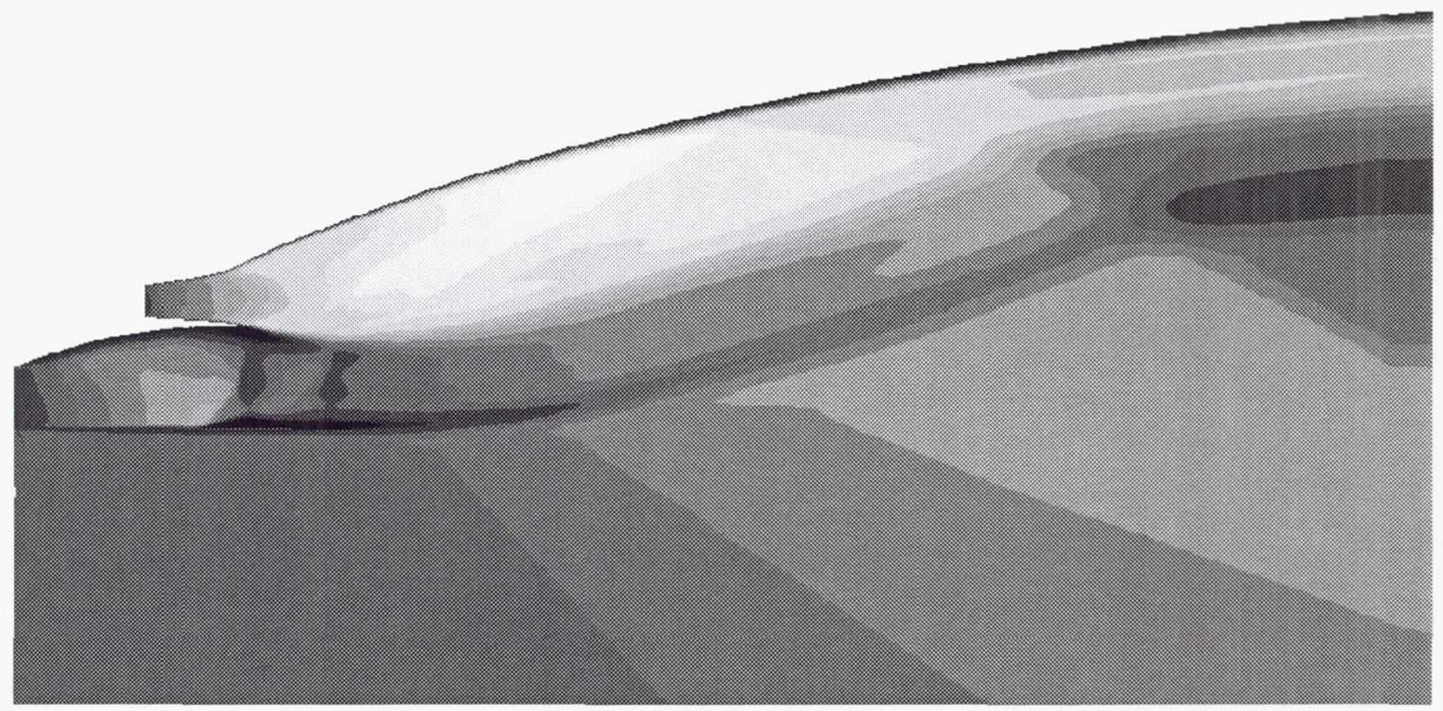

Mach number contour

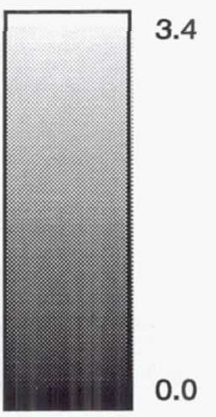

Figure 14.-Mach number contours for two-dimensional case in viscous mode.

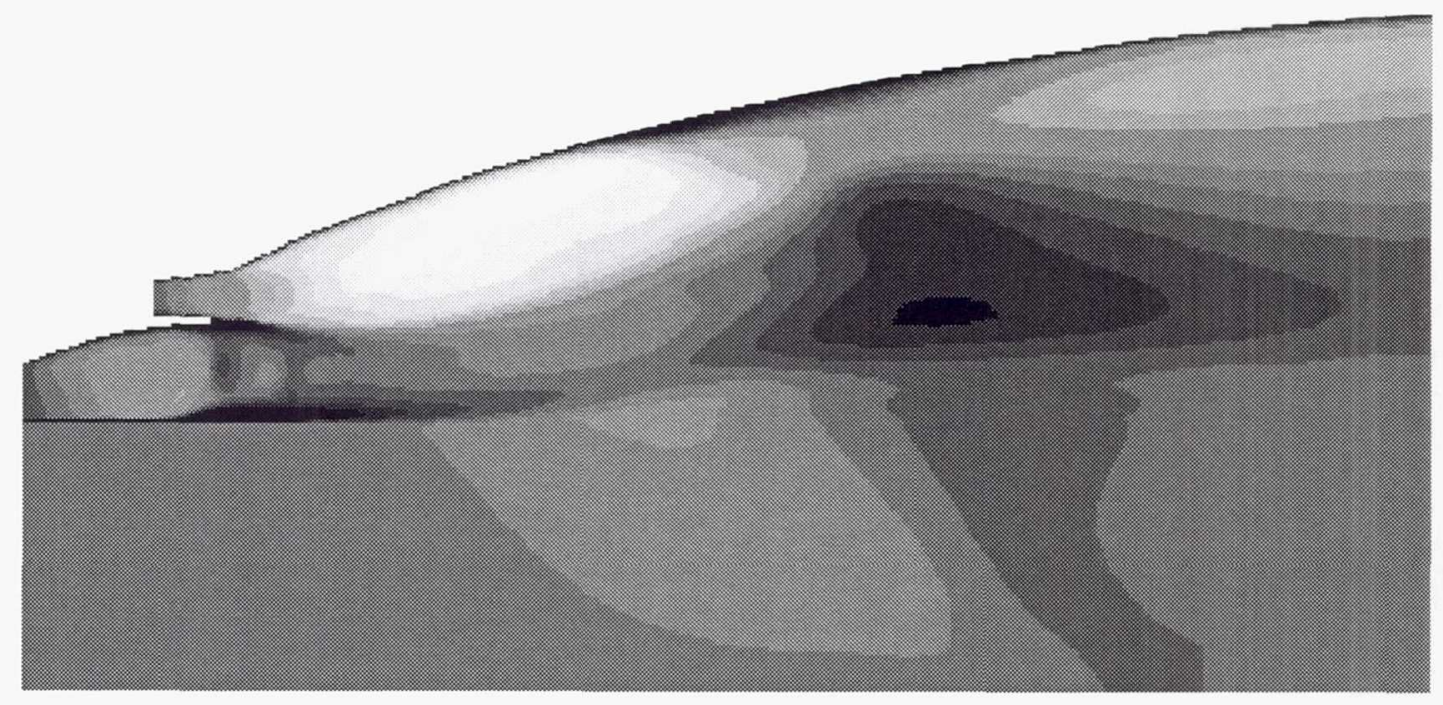

Mach number contour

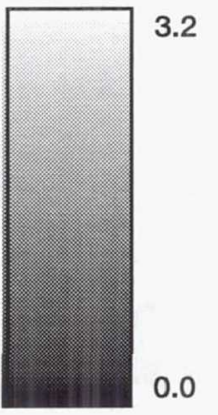

Figure 15.-Mach number contours along centerplane for three-dimensional case in viscous mode. 


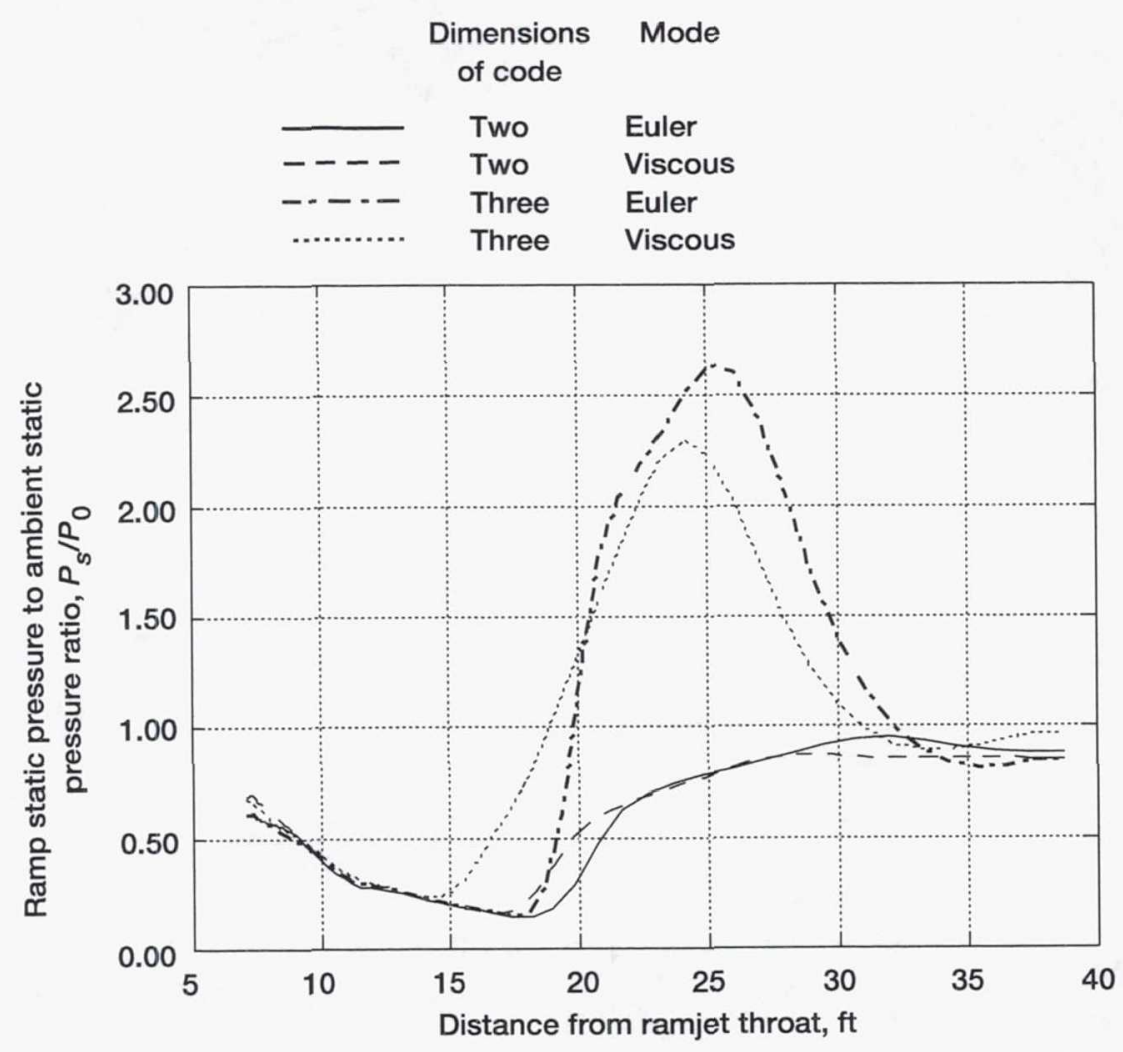

Figure 16.-Comparison of ramp pressure distributions for baseline configuration. 


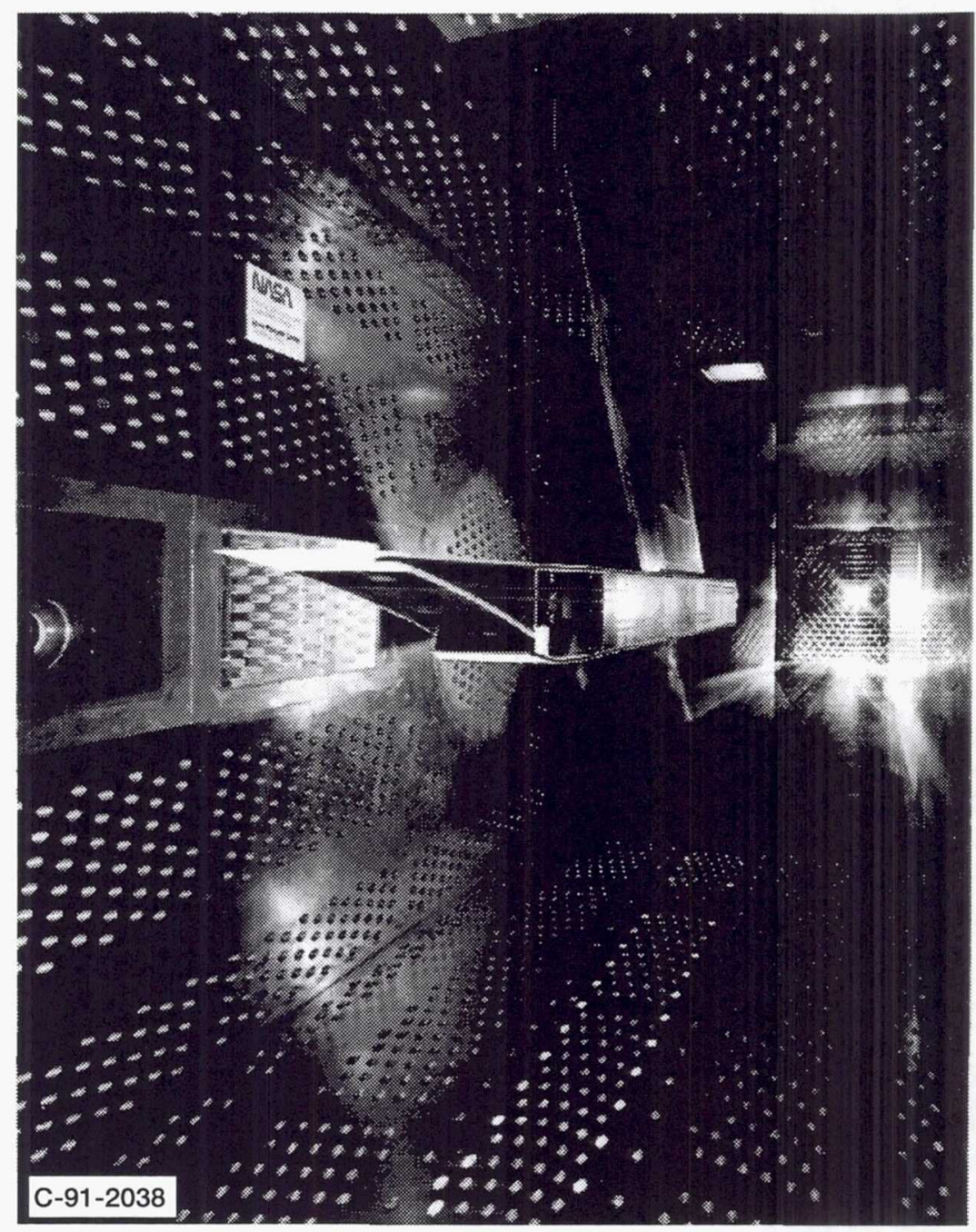

Figure 17.-Single-flow Single-expansion-ramp nozzle (SERN) configuration in the 8-Foot by 6-Foot Supersonic Wind Tunnel. 


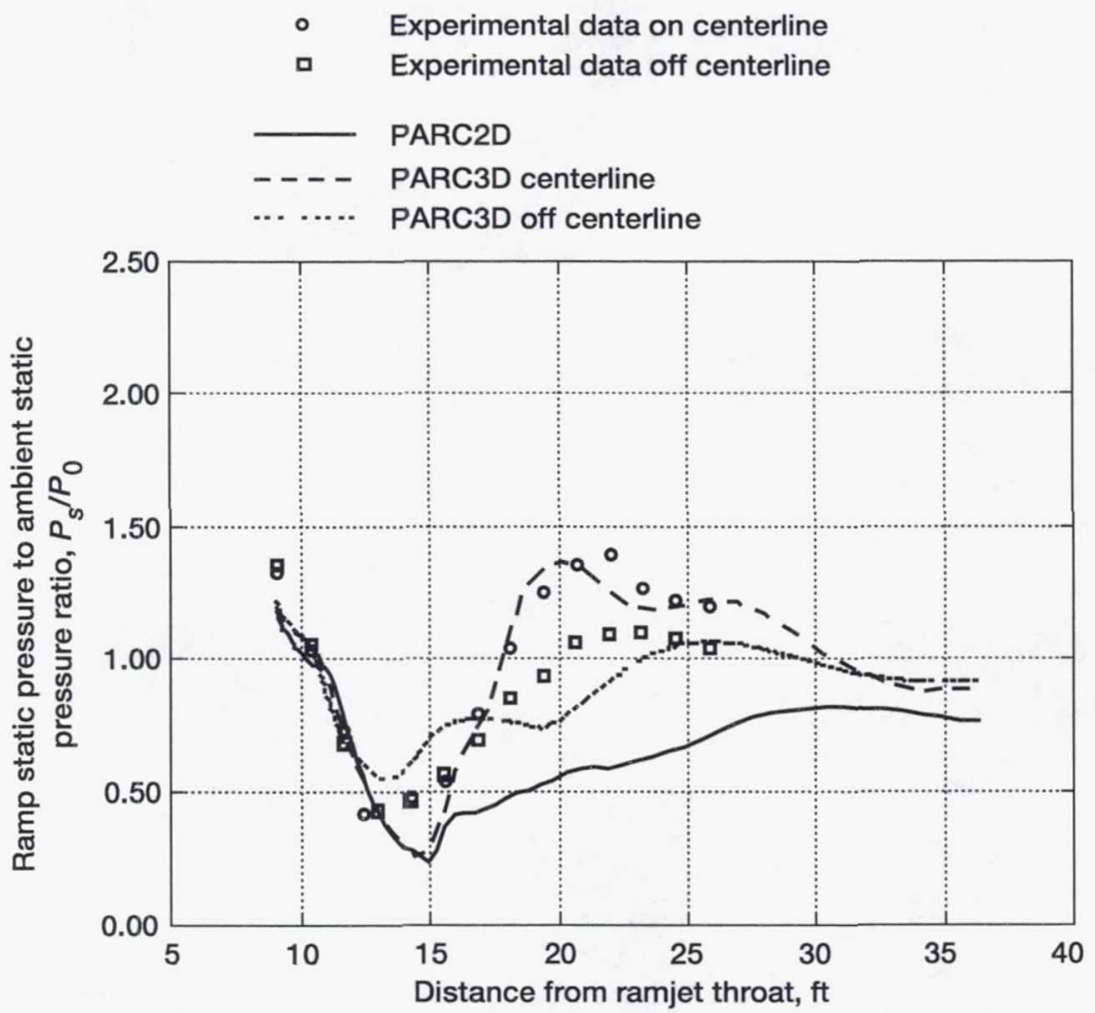

Figure 18.-Comparison of ramp pressure distributions for National Aerospace Plane (NASP) configuration at tunnel Mach number of 1.2 and NPR of 10. 
Public reporting burden for this collection of information is estimated to average 1 hour per response, including the time for reviewing instructions, searching existing data sources, Collection of information, including suggestions for reducing this burden, to Washington Headquarters Services, Directorate for Information Operations and Reports, 1215 Jefl
Davis Highway, Suite 1204, Arlington, VA 22202-4302, and to the Office of Management and Budget, Paperwork Reduction Project (0704-0188). Washington, DC 20503.

\begin{tabular}{|l|l|l|}
\hline 1. AGENCY USE ONLY (Leave blank) & $\begin{array}{c}\text { 2. REPORT DATE } \\
\text { July } 1995\end{array}$ & $\begin{array}{r}\text { 3. REPORT TYPE AND DATES COVERED } \\
\text { Technical Memorandum }\end{array}$ \\
\hline
\end{tabular}

4. TITLE AND SUBTITLE

Use of the PARC Code to Estimate the Off-Design Transonic Performance of an Over/Under Turboramjet Nozzle

6. $A U T H O R(S)$

David W. Lam

7. PERFORMING ORGANIZATION NAME(S) AND ADDRESS(ES)

National Aeronautics and Space Administration

Lewis Research Center

Cleveland, Ohio 44135-3191

9. SPONSORING/MONITORING AGENCY NAME(S) AND ADDRESS(ES)

National Aeronautics and Space Administration

Washington, D.C. 20546-0001

\section{SUPPLEMENTARY NOTES}

Prepared for the 31st Joint Propulsion Conference and Exhibit cosponsored by the AIAA, ASME, SAE, and ASEE, San Diego, California, July 10-12, 1995. Responsible person, David W. Lam, organization code 2740, (216) 433-8875.
WU-505-70-62

8. PERFORMING ORGANIZATION REPORT NUMBER

E-9638
10. SPONSORING/MONITORING AGENCY REPORT NUMBER

NASA TM-106924

AIAA-95-2616 12a. DISTRIBUTION/AVAILABILITY STATEMENT

Unclassified - Unlimited

Subject Category 02

This publication is available from the NASA Center for Aerospace Information, (301) 621-0390. 12b. DISTRIBUTION CODE

13. ABSTRACT (Maximum 200 words)

The transonic performance of a dual-throat, single-expansion-ramp nozzle (SERN) was investigated with the PARC computational fluid dynamics (CFD) code, an external flow Navier-Stokes solver. The nozzle configuration was from a conceptual Mach 5 cruise aircraft powered by four air-breathing turboramjets. Initial test cases used the two-dimensional version of PARC in Euler mode to investigate the effect of geometric variation on transonic performance. Additional cases used the two-dimensional version in viscous mode and the three-dimensional version in both Euler and viscous modes. Results of the analysis indicate low nozzle performance and a highly three-dimensional nozzle flow at transonic conditions. In another comparative study using the PARC code, a single-throat SERN configuration for which experimental data were available at transonic conditions was used to validate the results of the over/under turboramjet nozzle.

14. SUBJECT TERMS

15. NUMBER OF PAGES

18

PARC; Transonic performance; Over/under nozzle; Turboramjet

17. SECURITY CLASSIFICATION OF REPORT

Unclassified
18. SECURITY CLASSIFICATION OF THIS PAGE

Unclassified
19. SECURITY CLASSIFICATION OF ABSTRACT Unclassified 